\title{
Eplerenone and new-onset diabetes in patients with mild heart failure: results from the Eplerenone in Mild Patients Hospitalization and Survival Study in Heart Failure (EMPHASIS-HF)
}

\author{
David Preiss ${ }^{1}$, Dirk J. van Veldhuisen ${ }^{2}$, Naveed Sattar ${ }^{1}$, Henry Krum ${ }^{3}$, Karl Swedberg ${ }^{4}$, \\ Harry Shi ${ }^{5}$, John Vincent ${ }^{5}$, Stuart J. Pocock ${ }^{6}$, Bertram Pitt ${ }^{7}$, Faiez Zannad ${ }^{8}$, and \\ John J.V. McMurray ${ }^{1 *}$
}

${ }^{1}$ British Heart Foundation Cardiovascular Research Centre, University of Glasgow, Glasgow G12 8TA, UK; ${ }^{2}$ Department of Cardiology, Thorax Center, University Medical Center, Groningen, The Netherlands; ${ }^{3}$ Department of Epidemiology and Preventive Medicine, Centre of Cardiovascular Research and Education in Therapeutics, Monash University, Melbourne, Australia; ${ }^{4}$ Department of Emergency and Cardiovascular Medicine, Sahlgrenska Academy, University of Gothenburg, Gothenburg, Sweden; ${ }^{5}$ Pfizer, New York, USA; ${ }^{6}$ Department of Medical Statistics, London School of Hygiene and Tropical Medicine, London, UK; ${ }^{7}$ University of Michigan School of Medicine, Ann Arbor, MI, USA; and ${ }^{8}$ INSERM, Centre d'Investigation Clinique 9501 and Unité 961, Centre Hospitalier Universitaire, and the Department of Cardiology, Nancy University, Nancy, France

Received 7 February 2012; revised 29 March 2012; accepted 6 April 2012; online publish-ahead-of-print 19 May 2012

Aims

No studies have examined the effect of mineralocorticoid receptor antagonist therapy on new-onset diabetes. In addition, though the combination of diabetes and chronic heart failure (CHF) carries a poor prognosis, few studies have examined predictors of new-onset diabetes in those with CHF.

Methods and results

Conclusions

Keywords
In patients with symptomatically mild CHF who participated in the placebo-controlled Eplerenone in Mild Patients Hospitalization and Survival Study in Heart Failure, we examined the effect of the aldosterone antagonist, eplerenone, on physician-diagnosed diabetes using univariate Cox proportional hazard analysis. To identify predictors of newonset diabetes (measures of glycaemia were not available), data from trial arms were combined and multivariate Cox proportional hazard analyses and receiver operating characteristic curve analyses were conducted. At baseline, the mean age of 1846 initially non-diabetic patients was 69 years and mean left ventricular ejection fraction was $26 \%$. Over 21 months, 69 (3.7\%) developed diabetes (33 on eplerenone, 36 on placebo). Eplerenone had no effect on new-onset diabetes [hazard ratio (HR) $0.94,95 \%$ confidence interval $(\mathrm{Cl})$ 0.59-1.52] and no effect on the composite of new-onset diabetes or mortality ( $\mathrm{HR} 0.80,95 \% \mathrm{Cl} 0.64-1.01)$. Independent predictors of new-onset diabetes included digoxin therapy, higher serum alanine aminotransferase, longer duration of heart failure, current or previous smoker, higher waist circumference, lower age, and higher systolic blood pressure with a combined c-statistic of 0.74 . Eplerenone had no effect on new-onset diabetes in patients with $\mathrm{CHF}$, but further large-scale studies are required to address this question comprehensively. Commonly recorded parameters provided useful information for predicting new-onset diabetes.

Keywords: Chronic heart failure • Diabetes • Prediction • Eplerenone

\section{Introduction}

Patients with heart failure are at increased risk of developing newonset diabetes mellitus, and co-existent diabetes is associated with worse heart failure symptoms, higher rates of hospitalization, and reduced survival. ${ }^{1}$ Why the risk of incident diabetes is increased in heart failure is uncertain, and relatively little is known about the variables predicting this risk. To date, only the Candesartan

* Corresponding author. Tel: +44 141 3303479; fax: +44 141 3306955, Email: john.mcmurray@glasgow.ac.uk 
in Heart Failure: Assessment of Reduction in Mortality and Morbidity (CHARM) and Carvedilol Or Metoprolol European Trial (COMET) trials have examined this question. ${ }^{2,3}$ It is known, however, that angiotensin II receptor blockers (ARBs), and possibly angiotensin-converting enzyme (ACE) inhibitors, reduce the risk of developing diabetes in patients with heart failure (and also in those with hypertension and impaired glucose tolerance). ${ }^{4-6} \mathrm{It}$ is therefore of interest to know whether the other type of renin-angiotensin-aldosterone blockers used in heart failure, mineralocorticoid receptor (MR) antagonists, affect the risk of incident diabetes. Data on the effect of MR antagonists on glycaemic indices are conflicting. Treatment with the non-selective MR antagonist, spironolactone, has consistently been associated with elevations in haemoglobin $\mathrm{A} 1 \mathrm{c}\left(\mathrm{HbA}_{1 \mathrm{c}}\right)$ in patients with and without diabetes, ${ }^{7-10}$ suggesting that spironolactone may increase the risk of new-onset diabetes. In contrast, spironolactone has been shown to improve insulin sensitivity in patients with non-alcoholic fatty liver disease (NAFLD), a condition closely associated with insulin resistance. ${ }^{11}$ Even less is known about the actions of the more selective MR antagonist eplerenone. However, in one trial comparing the effects of spironolactone and eplerenone in patients with chronic heart failure, spironolactone recipients showed increases in both $\mathrm{HbA}_{1 \mathrm{c}}$ and cortisol levels, plus a fall in adiponectin, whereas no changes occurred in eplerenone recipients. ${ }^{7}$

New-onset diabetes was a pre-defined secondary endpoint in the Eplerenone in Mild Patients Hospitalization and Survival Study in Heart Failure (EMPHASIS-HF). In this report we describe the effect of eplerenone, compared with placebo, on new-onset diabetes and the baseline predictors of incident diabetes.

\section{Methods}

The primary aim of EMPHASIS-HF was to investigate the effect of eplerenone, added to evidence-based therapy, on clinical outcomes in patients with systolic heart failure and mild symptoms [patients had to be in New York Heart Association (NYHA) functional class II]. The design, protocol, and results of the trial are available elsewhere. ${ }^{12,13}$ Briefly, 2737 patients with mild symptoms and a left ventricular ejection fraction $\leq 0.35$ were randomized to receive either the aldosterone antagonist, eplerenone (up to $50 \mathrm{mg}$ daily), or placebo in addition to recommended therapy (including an ACE inhibitor or ARB and beta-blocker). Patients were followed up for a median of 21 months to assess the effect on a composite outcome of cardiovascular death or hospitalization for heart failure. Patients were seen 4 weeks after randomization and then every 4 months during trial follow-up. All patients provided written informed consent and the protocol was approved by the ethics committee at each participating institution. The trial was supported by the study sponsor, Pfizer.

\section{Analysis population}

The analysis population included all EMPHASIS-HF participants in the full analysis set but excluding those known to have diabetes at baseline.

Diabetes status at baseline was determined from the following parts of the study case report form: (i) significant medical condition report at screening; (ii) the aetiology of heart failure report and prior index hospitalization at screening; (iii) the medical history page; and (iv) use of medications for diabetes in the 3 months prior to screening or at the randomization visit.

\section{Diagnosis of new-onset diabetes}

Incident diabetes was a pre-specified secondary endpoint in EMPHASIS-HF. Investigators were asked to check for (and report) the occurrence of a new diagnosis of diabetes at each postrandomization trial visit. Details of the diagnosis of diabetes [date of diagnosis, details of the criteria for diagnosis [elevated fasting plasma glucose $(\geq 7.0 \mathrm{mmol} / \mathrm{L})$, random glucose $(\geq 11.1 \mathrm{mmol} / \mathrm{L})$, or oral glucose tolerance test (fasting plasma glucose $\geq 7.0 \mathrm{mmol} / \mathrm{L}$ and/or $2 \mathrm{~h}$ plasma glucose $\geq 11.1 \mathrm{mmol} / \mathrm{L})]$, hypoglycaemic medication prescribed, and lifestyle modifications prescribed were documented on a specific incident diabetes case report form. Fasting blood samples were not collected in EMPHASIS-HF and formal tests for diabetes were not performed.

\section{Statistical methods}

To assess the effect of eplerenone on new-onset diabetes in patients without diabetes at baseline, the numbers of subjects developing diabetes in each treatment arm were compared in a univariate Cox proportional hazard analysis, with treatment allocation (eplerenone or placebo) as the only factor in the model. Cumulative event rates for new-onset diabetes were compared using the log rank test. In an attempt to exclude any potential effect of competing risk introduced by an effect of eplerenone on mortality, an additional composite endpoint of all-cause mortality or new-onset diabetes was analysed.

To identify independent predictors of new-onset diabetes, data from both treatment arms were pooled. Numerous commonly recorded demographic, clinical, laboratory, and medication variables at baseline were considered as predictors of diabetes (see Table 1). Patients who did and did not develop diabetes during the trial were compared with respect to these baseline variables using two-sample $t$-tests (for continuous variables) and Fisher's exact tests (for categorical variables). Univariate Cox proportional hazard analyses were employed to assess the strength of association between each of these baseline variables and new-onset diabetes. In subsequent multivariate Cox proportional hazard analyses to identify independent predictors, two approaches were used. In the first approach, a full multivariate Cox proportional hazard model (Model 1) was built by including all variables associated with new-onset diabetes $(P<0.10$ identified from univariate Cox proportional hazard analyses) but for highly correlated variables [e.g. body mass index (BMI), waist circumference, and weight] only the variable that provided the most information was included. In the second approach, a reduced multivariate model (Model 2) was established from the full multivariate Cox proportional hazard model (Model 1) using a stepwise selection process to identify relevant variables. For the univariate and multivariate analyses, hazard ratios (HRs) for new-onset diabetes are provided per one standard deviation of each continuous variable to facilitate comparison. Finally, receiver operating characteristic (ROC) curve analysis was performed to calculate the c-statistics for both Models 1 and 2.

All $P$-values were two sided, and $P<0.05$ was considered statistically significant. Analyses were performed using Statistical Analysis Software (SAS, Window Version V8).

\section{Results}

Of the 2737 patients randomized in EMPHASIS-HF, 891 (32.5\%) were known to have diabetes at baseline. Analyses in this report are limited to the 1846 patients without known diabetes at baseline. The average age was 69 years and average BMI was $27 \mathrm{~kg} / \mathrm{m}^{2}$. During the 21 months of follow-up, 69 (3.7\%) of the 1846 patients without 
Table I Baseline characteristics of EMPHASIS-HF participants with mild heart failure and no history of diabetes at baseline, split into those who did and did not develop diabetes during the trial

\begin{tabular}{|c|c|c|c|c|}
\hline Variable & & $\begin{array}{l}\text { No new-onset DM (SD or \%) } \\
n=1777\end{array}$ & $\begin{array}{l}\text { New-onset DM (SD or \%) } \\
n=69\end{array}$ & $P$-value* \\
\hline Age (years) & & $68.9(7.8)$ & $66.9(7.2)$ & 0.037 \\
\hline Gender (male) & & $1377(77.5)$ & $58(84.1)$ & 0.24 \\
\hline \multirow[t]{4}{*}{ Race } & White & $1523(85.7)$ & $64(92.8)$ & 0.35 \\
\hline & Black & $50(2.8)$ & $0(0)$ & - \\
\hline & Asian & $151(8.5)$ & $3(4.3)$ & - \\
\hline & Other & $50(2.8)$ & $2(2.9)$ & - \\
\hline \multirow[t]{3}{*}{ Smoking status } & Never & $800(45.0)$ & $21(30.4)$ & 0.040 \\
\hline & Current & $202(11.4)$ & $8(11.6)$ & - \\
\hline & Previous & $775(43.6)$ & $40(58.0)$ & - \\
\hline HF aetiology: ischaemia & & $1160(65.3)$ & $45(65.2)$ & 1.00 \\
\hline Duration of HF (years) & & $4.4(5.8)$ & $6.0(6.4)$ & 0.021 \\
\hline Left ventricular ejection fraction (\%) & & $25.9(4.7)$ & $26.5(4.4)$ & 0.38 \\
\hline \multirow[t]{6}{*}{ Demographicsvitals } & BMI $\left(\mathrm{kg} / \mathrm{m}^{2}\right)$ & $27.0(4.6)$ & $29.3(4.9)$ & 0.0001 \\
\hline & $\mathrm{SBP}(\mathrm{mmHg})$ & $123.3(16.8)$ & $129.0(15.3)$ & 0.0054 \\
\hline & $\mathrm{DBP}(\mathrm{mmHg})$ & $74.5(10.2)$ & $77.9(9.0)$ & 0.0061 \\
\hline & Heart rate (b.p.m.) & $72.5(15.8)$ & $77.7(15.2)$ & 0.0073 \\
\hline & Waist circumference $(\mathrm{cm})$ & $97.8(13.4)$ & $104.0(11.6)$ & 0.0002 \\
\hline & Weight (kg) & $78.0(16.2)$ & $85.4(15.4)$ & 0.0002 \\
\hline \multirow[t]{5}{*}{ Past medical history } & Hypertension & $1098(61.8)$ & $53(76.8)$ & 0.0112 \\
\hline & Previous MI & $849(47.8)$ & $33(47.8)$ & 1.00 \\
\hline & Atrial fibrillation & $571(32.1)$ & $31(44.9)$ & 0.035 \\
\hline & LBBB on ECG & $444(25.0)$ & 15 (21.7) & 0.67 \\
\hline & QRS duration (ms) & $122.9(46.6)$ & $121.4(48.3)$ & 0.79 \\
\hline \multirow[t]{7}{*}{ Laboratory } & Albumin (g/dL) & $4.1(0.5)$ & $4.1(0.4)$ & 0.80 \\
\hline & $\operatorname{ALT}(I \cup / L)$ & $27.2(16.8)$ & $34.9(22.8)$ & 0.0079 \\
\hline & AST (IU/L) & $26.7(14.0)$ & $31.7(20.6)$ & 0.052 \\
\hline & Creatinine (mg/dL) & $1.1(0.3)$ & $1.1(0.3)$ & 0.45 \\
\hline & eGFR $\left(\mathrm{mL} / \mathrm{min} / 1.73 \mathrm{~m}^{2}\right)$ & $71.6(21.7)$ & $71.9(18.8)$ & 0.91 \\
\hline & Potassium (mmol/L) & $4.3(0.4)$ & $4.4(0.4)$ & 0.023 \\
\hline & Bilirubin (mg/dL) & $0.8(0.4)$ & $0.7(0.3)$ & 0.11 \\
\hline \multirow[t]{7}{*}{ Medications } & ACE inhibitor & $1429(80.4)$ & $56(81.2)$ & 1.00 \\
\hline & ARB & $316(17.8)$ & $17(24.6)$ & 0.15 \\
\hline & Lipid-lowering agent & $1094(61.6)$ & $41(59.4)$ & 0.71 \\
\hline & ACE inhibitor or $A R B$ & $1699(95.6)$ & $69(100)$ & 0.12 \\
\hline & Beta-blocker & $1544(86.9)$ & $55(79.7)$ & 0.10 \\
\hline & Digitalis & $450(25.3)$ & $32(46.4)$ & 0.0002 \\
\hline & Diuretic & $1515(85.3)$ & $62(89.9)$ & 0.38 \\
\hline
\end{tabular}

Data provided as $n(\%)$ or mean (SD).

ACE, angiotensin-converting enzyme; ALT, alanine aminotransferase; ARB, angiotensin receptor blocker; AST, aspartate aminotransferase; BMI, body mass index; DBP, diastolic blood pressure; DM, diabetes mellitus; ECG, electrocardiogram; eGFR, estimated glomerular filtration rate; HF, heart failure; LBBB, left bundle branch block; MI, myocardial infarction; SBP, systolic blood pressure.

*Based on two-sample $t$-tests for continuous variables and Fisher's exact tests for categorical variables. 


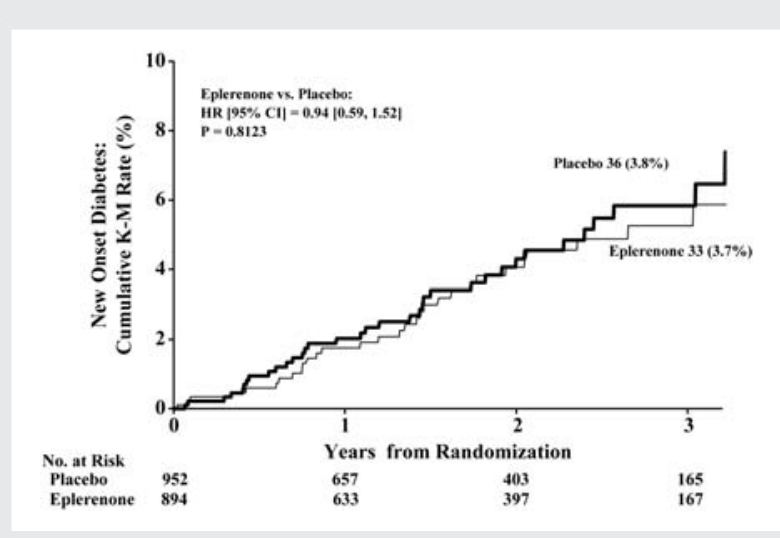

Figure I Kaplan-Meier plot for new-onset diabetes on eplerenone compared with placebo in EMPHASIS-HF.

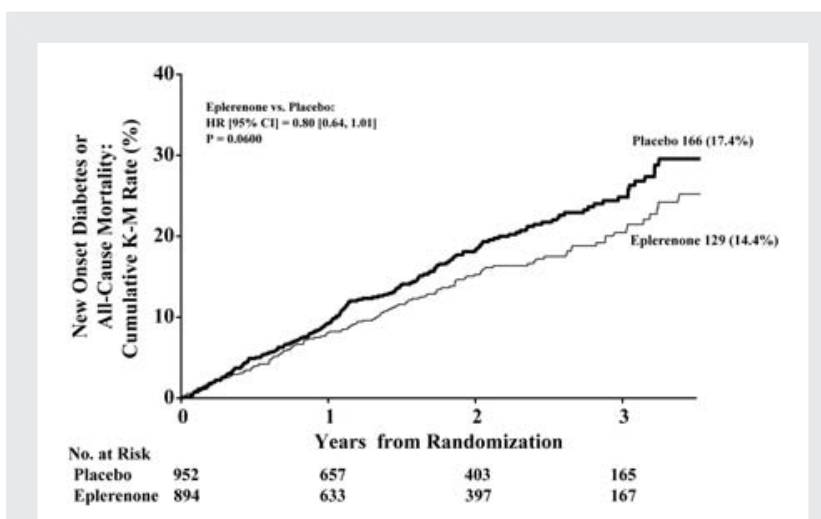

Figure 2 Kaplan-Meier plot for the composite endpoint of new-onset diabetes or mortality on eplerenone compared with placebo in EMPHASIS-HF.

diabetes at baseline were diagnosed with diabetes, an approximate incidence of 21 cases per 1000 patient-years.

\section{Effect of eplerenone on new-onset diabetes}

The baseline characteristics of patients without diabetes at baseline were balanced between randomized treatment arms (Supplementary material online, Table S1). Eplerenone had no effect on the incidence of new-onset diabetes; 33 (3.7\%) of 894 patients assigned to treatment with eplerenone developed diabetes compared with 36 (3.8\%) of 952 patients assigned placebo (Figure 1). This corresponded to a HR of 0.94 [95\% confidence interval $(\mathrm{Cl}) 0.59-$ 1.52, $P=0.81]$. The eplerenone:placebo HR for the composite of all-cause mortality or new-onset diabetes was $0.80(95 \% \mathrm{Cl}$ $0.64-1.01$ ); $P=0.06$ (Figure 2).

\section{Predictors of new-onset diabetes in mild heart failure}

The baseline characteristics of patients who did and did not develop new diabetes are shown in Table 1. In univariate Cox proportional hazard analysis, the strongest predictors of new-onset diabetes (in decreasing order of magnitude as estimated by the Wald $\chi^{2}$ statistic) were: higher serum alanine aminotransferase (ALT), use of digitalis, higher serum aspartate aminotransferase (AST), higher waist circumference, higher weight, higher BMI,

Table 2 Association of baseline characteristics with new-onset diabetes using univariate Cox proportional hazard analysis (expressed per one standard deviation for continuous variables) in patients with mild heart failure

\begin{tabular}{|c|c|c|c|}
\hline Characteristic & $\begin{array}{l}\chi^{2} \\
\text { statistic }\end{array}$ & $\begin{array}{l}\text { Hazard ratio } \\
(95 \% \mathrm{Cl})\end{array}$ & $P$-value \\
\hline ALT (IU/L) & 16.79 & $1.39(1.19-1.62)$ & $<0.0001$ \\
\hline Digitalis & 15.01 & 2.55 (1.59-4.09) & 0.0001 \\
\hline AST (IU/L) & 14.78 & $1.36(1.16-1.60)$ & 0.0001 \\
\hline $\begin{array}{l}\text { Waist circumference } \\
\qquad(\mathrm{cm})\end{array}$ & 13.09 & $1.54(1.22-1.95)$ & 0.0003 \\
\hline Weight $(\mathrm{kg})$ & 11.99 & $1.49(1.19-1.86)$ & 0.0005 \\
\hline BMI $\left(\mathrm{kg} / \mathrm{m}^{2}\right)$ & 11.47 & $1.43(1.16-1.77)$ & 0.0007 \\
\hline Duration of HF (years) & 8.20 & $1.32(1.09-1.59)$ & 0.0042 \\
\hline $\begin{array}{l}\text { Smoking status (current } \\
\text { or ex-smoker vs. } \\
\text { never) }\end{array}$ & 7.02 & $2.00(1.20-3.34)$ & 0.0081 \\
\hline Heart rate (b.p.m.) & 6.87 & $1.30(1.07-1.59)$ & 0.0088 \\
\hline Hypertension & 6.27 & $2.04(1.17-3.57)$ & 0.012 \\
\hline $\mathrm{SBP}(\mathrm{mmHg})$ & 6.10 & $1.34(1.06-1.69)$ & 0.0135 \\
\hline Age (years) & 5.97 & $0.72(0.55-0.94)$ & 0.015 \\
\hline $\mathrm{DBP}(\mathrm{mmHg})$ & 5.70 & $1.33(1.05-1.68)$ & 0.017 \\
\hline Potassium (mmol/L) & 4.52 & $1.32(1.02-1.70)$ & 0.034 \\
\hline Beta-blocker & 4.10 & $0.55(0.30-0.98)$ & 0.043 \\
\hline Atrial fibrillation & 3.97 & $1.62(1.01-2.60)$ & 0.046 \\
\hline ARB & 2.32 & $1.53(0.89-2.65)$ & 0.13 \\
\hline $\begin{array}{l}\text { Gender (male vs. } \\
\text { female) }\end{array}$ & 1.64 & $1.52(0.80-2.90)$ & 0.20 \\
\hline Bilirubin (mg/dL) & 1.48 & $0.83(0.61-1.12)$ & 0.22 \\
\hline Race (white vs. other) & 0.85 & $1.53(0.62-3.82)$ & 0.36 \\
\hline LBBB on ECG & 0.55 & $0.81(0.45-1.43)$ & 0.46 \\
\hline LVEF (\%) & 0.54 & $1.10(0.85-1.44)$ & 0.46 \\
\hline Creatinine (mg/dL) & 0.30 & $0.93(0.73-1.20)$ & 0.59 \\
\hline Lipid-lowering agent & 0.15 & $0.91(0.56-1.47)$ & 0.70 \\
\hline Previous MI & 0.12 & $1.09(0.68-1.75)$ & 0.73 \\
\hline ACE inhibitor & 0.11 & $0.90(0.49-1.65)$ & 0.74 \\
\hline Albumin (g/dL) & 0.076 & $0.97(0.76-1.23)$ & 0.78 \\
\hline $\begin{array}{l}\text { Heart failure aetiology } \\
\text { (ischaemia vs. other) }\end{array}$ & 0.036 & $0.95(0.58-1.56)$ & 0.85 \\
\hline QRS duration (ms) & 0.029 & $1.02(0.81-1.28)$ & 0.87 \\
\hline $\begin{array}{l}\text { eGFR }(\mathrm{mL} / \mathrm{min} / \\
\left.1.73 \mathrm{~m}^{2}\right)\end{array}$ & 0.005 & $0.99(0.78-1.27)$ & 0.94 \\
\hline
\end{tabular}

The $\chi^{2}$ statistic, hazard ratio, $95 \% \mathrm{Cl}$, and $P$-values are based on univariate Cox proportional hazard analysis.

$\mathrm{ACE}$, angiotensin-converting enzyme; ALT, alanine aminotransferase; ARB, angiotensin receptor blocker; AST, aspartate aminotransferase; BMI, body mass index; $\mathrm{Cl}$, confidence interval; DBP, diastolic blood pressure; ECG, electrocardiogram; eGFR, estimated glomerular filtration rate; $\mathrm{HF}$, heart failure; LBBB, left bundle branch block; LVEF, left ventricular ejection fraction; MI, myocardial infarction; SBP, systolic blood pressure. 
Table 3 Prediction of new-onset diabetes in patients with mild heart failure using multivariate Cox proportional hazard analysis (expressed per one standard deviation for continuous variables)

\begin{tabular}{|c|c|c|c|c|c|c|}
\hline \multirow[t]{2}{*}{ Variable } & \multicolumn{3}{|c|}{$\begin{array}{l}\text { Multivariate Cox proportional hazards } \\
\text { (Model 1) }\end{array}$} & \multicolumn{3}{|c|}{$\begin{array}{l}\text { Multivariate Cox model with stepwise } \\
\text { selection (Model 2) }\end{array}$} \\
\hline & $x^{2}$ & Hazard ratio $(95 \% \mathrm{Cl})$ & $P$-value & $x^{2}$ & Hazard ratio $(95 \% \mathrm{Cl})$ & $P$-value \\
\hline Digitalis & 9.88 & $2.37(1.38-4.06)$ & 0.002 & 14.30 & $2.59(1.58-4.24)$ & 0.0002 \\
\hline ALT (IU/L) & 9.49 & $1.36(1.12-1.64)$ & 0.002 & 10.59 & $1.36(1.13-1.63)$ & 0.001 \\
\hline Heart failure duration (years) & 9.06 & $1.38(1.12-1.69)$ & 0.003 & 9.87 & $1.39(1.13-1.71)$ & 0.002 \\
\hline Smoking (current/past vs. never) & 6.25 & $1.99(1.16-3.41)$ & 0.012 & 5.85 & $1.93(1.13-3.28)$ & 0.016 \\
\hline Waist circumference $(\mathrm{cm})$ & 5.78 & $1.38(1.06-1.79)$ & 0.016 & 10.58 & $1.51(1.18-1.93)$ & 0.001 \\
\hline Age (years) & 5.18 & $0.71(0.53-0.95)$ & 0.023 & 4.52 & $0.73(0.55-0.98)$ & 0.034 \\
\hline SBP $(\mathrm{mmHg})$ & 4.64 & $1.32(1.03-1.69)$ & 0.031 & 7.18 & $1.38(1.09-1.75)$ & 0.007 \\
\hline Hypertension & 2.78 & $1.67(0.91-3.06)$ & 0.10 & - & - & - \\
\hline Potassium (mmol/L) & 2.29 & $1.22(0.94-1.59)$ & 0.13 & - & - & - \\
\hline Heart rate (b.p.m.) & 1.59 & $1.16(0.92-1.45)$ & 0.21 & - & - & - \\
\hline Beta-blockers & 0.71 & $0.75(0.39-1.46)$ & 0.40 & - & - & - \\
\hline Atrial fibrillation & 0.16 & $1.12(0.65-1.94)$ & 0.69 & - & - & - \\
\hline
\end{tabular}

The $\chi^{2}$ statistic, hazard ratio, $95 \% \mathrm{Cl}$, and $P$-values are based on multivariate Cox proportional hazard analysis including all predictor variables with $P<0.10$ in univariate analysis. For the following highly correlated variables, the following variables were selected by a stepwise process:

- Systolic and diastolic blood pressure: systolic blood pressure included.

-Weight, waist circumference. and BMI: waist circumference selected.

-ALT and AST: ALT selected.

ALT, alanine aminotransferase; AST, aspartate aminotransferase; $\mathrm{BMI}$, body mass index; $\mathrm{Cl}$, confidence interval; SBP, systolic blood pressure.

longer duration of heart failure, current or previous smoking, higher heart rate, hypertension, higher systolic blood pressure, lower age, higher diastolic blood pressure, higher serum potassium, not using a beta-blocker. and the presence of atrial fibrillation (see Table 2).

In multivariable Cox proportional hazard analysis, Model 1 [full model where only variables with $P<0.10$ in univariate analysis were included but for the following groups of highly correlated variables only the variable that provided the most information was included: (i) systolic and diastolic blood pressure: systolic blood pressure selected; (ii) weight, waist circumference, and BMI: waist circumference selected; (iii) ALT and AST: ALT selected], only seven variables remained significantly associated with new-onset diabetes (see Table 3). These independent predictors of new-onset diabetes (in decreasing order of magnitude as estimated by the Wald $\chi^{2}$ statistic) were: use of digitalis, higher serum ALT, longer heart failure duration, current or previous smoking, higher waist circumference, lower age, and higher systolic blood pressure. Variables identified in Model 2 (the reduced model) were similar.

In the ROC curve analysis, the individual c-statistic for variables independently associated with new-onset diabetes varied from 0.53 to 0.65 in Models 1 and 2. When all the relevant variables were combined, the overall c-statistic was 0.74 for Model 1 and 0.76 for Model 2 (see Table 4).

\section{Discussion}

That diabetes is common in patients with heart failure ${ }^{1}$ was confirmed in the present study. Thirty-two per cent of participants had diabetes at baseline, and in those without diabetes at baseline the incidence of new diabetes was 21 cases per 1000 patient-years of follow-up. This incidence is similar to that reported in two other clinical trials in chronic heart failure ${ }^{2,3}$ and is considerably higher than expected in the general population, e.g. the incidence of physician-diagnosed diabetes was 12.8 cases per 1000 patient-years in American adults aged 65-79 years in 2009. ${ }^{14}$

The effect of MR antagonists on the risk of diabetes is difficult to predict. Primary hyperaldosteronism is a state of insulin resistance, and aldosterone levels are associated with insulin resistance in normotensive and hypertensive patients. ${ }^{15}$ In an observational study of patients with primary hyperaldosteronism, treatment with either spironolactone or adrenalectomy returned insulin sensitivity parameters towards normal. ${ }^{16}$ In another study, the combination of vitamin $E$ and spironolactone for 8 weeks decreased insulin levels and Homeostasis Model Assessment of Insulin Resistance (HOMA-IR) compared with vitamin $\mathrm{E}$ alone in patients with biopsy-proven NAFLD, ${ }^{11}$ while spironolactone therapy has shown benefical cardiac effects in patients with metabolic syndrome. $^{17}$ Low serum potassium is also known to be associated with increased risk of new-onset diabetes in both normotensive and treated hypertensive patients, and MR antagonists increase potassium. ${ }^{18,19}$ On the other hand, spironolactone therapy has consistently led to modest increases in $\mathrm{HbA}_{1 \mathrm{c}}$ in clinical trials of patients with type 2 diabetes alone or complicated by nephropathy or poorly controlled hypertension. ${ }^{8-10}$ In a further study of 107 patients with mild chronic heart failure, spironolactone therapy increased $\mathrm{HbA}_{1 \mathrm{c}}$ and cortisol levels and reduced adiponectin levels over 4 months, ${ }^{7}$ findings which might be expected to herald an increased risk of developing diabetes. In contrast, in 
Table 4 Prediction of new-onset diabetes in patients with mild heart failure using receiver operating characteristic curve analysis for variables associated with new-onset diabetes

\begin{tabular}{|c|c|c|c|c|}
\hline \multirow[t]{2}{*}{ Variable } & \multicolumn{2}{|l|}{ Multivariate model 1} & \multicolumn{2}{|l|}{ Multivariate model 2} \\
\hline & c-statistic $(95 \% \mathrm{Cl})$ & $P$-value & c-statistic $(95 \% \mathrm{Cl})$ & $P$-value \\
\hline Age (years) & $0.586(0.517-0.656)$ & 0.014 & $0.586(0.517-0.656)$ & 0.014 \\
\hline Smoking (current/past vs. never) & $0.571(0.513-0.629)$ & 0.016 & $0.571(0.513-0.629)$ & 0.016 \\
\hline $\mathrm{SBP}(\mathrm{mmHg})$ & $0.599(0.535-0.664)$ & 0.0026 & $0.599(0.535-0.664)$ & 0.0026 \\
\hline Waist circumference $(\mathrm{cm})$ & $0.650(0.586-0.714)$ & $<0.0001$ & $0.650(0.586-0.714)$ & $<0.0001$ \\
\hline ALT (IU/L) & - & - & $0.596(0.524-0.668)$ & 0.0035 \\
\hline AST (IU/L) & $0.563(0.486-0.639)$ & 0.11 & - & - \\
\hline Heart failure duration (years) & $0.566(0.489-0.643)$ & 0.093 & $0.566(0.489-0.643)$ & 0.093 \\
\hline Digitalis & $0.600(0.538-0.662)$ & 0.0015 & $0.600(0.538-0.662)$ & 0.0015 \\
\hline Hypertension & $0.567(0.512-0.621)$ & 0.0158 & - & - \\
\hline Potassium (mmol/L) & $0.572(0.501-0.643)$ & 0.0464 & - & - \\
\hline Heart rate (b.p.m.) & $0.613(0.546-0.680)$ & 0.0010 & - & - \\
\hline Beta-blockers & $0.527(0.479-0.575)$ & 0.2706 & - & - \\
\hline Atrial fibrillation & $0.567(0.504-0.629)$ & 0.0357 & - & - \\
\hline Combined c-statistic & $0.764(0.708-0.821)$ & $<0.0001$ & $0.735(0.673-0.797)$ & $<0.0001$ \\
\hline
\end{tabular}

ALT, alanine aminotransferase; AST, aspartate aminotransferase; $\mathrm{Cl}$, confidence interval; SBP, systolic blood pressure.

that study eplerenone had no such effects, suggesting the possibility of a differential effect, depending on the selectivity of MR blockade. Consistent with this, we found no effect of eplerenone on incident diabetes in the present study, although the number of affected patients was relatively small.

We identified seven factors independently associated with newonset diabetes. Of these, longer duration of heart failure, higher serum ALT, and higher waist circumference were expected predictors. Serum ALT has been associated with incident diabetes in a number of studies in several different populations, including heart failure. ${ }^{2,20,21}$ Usually this is thought to be because ALT is considered a surrogate marker for NAFLD, a condition characterized by insulin resistance and therefore a powerful risk factor for diabetes. Whether or not this is the explanation in heart failure is less certain because transaminases may be elevated due to liver congestion or ischaemia. Interestingly, waist circumference performed slightly better as a predictor compared with either BMI or body weight. Digitalis was strongly predictive of new-onset diabetes, a finding noted in earlier studies but unexplained. ${ }^{2,3}$ One possibility is that digitalis use is a marker of heart failure severity, and there is some evidence that the risk of diabetes increases with increasing severity of heart failure. ${ }^{22}$ However, it has also been suggested that reduced activity of $\mathrm{Na} / \mathrm{K}$-ATPase may play a role in the pathogenesis of diabetes mellitus, and digoxin is an inhibitor of this enzyme. ${ }^{23,24}$ Lower age was also associated with higher risk of developing diabetes. Though at first sight surprising, this was noted in previous studies ${ }^{2,3}$ and seems likely to reflect either the different phenotypes of older and younger trial participants [data exist to support this: in a substudy of 2107 patients in CHARM, the prevalence of obesity (BMI $\geq 30 \mathrm{~kg} / \mathrm{m}^{2}$ ) was four times higher in patients with chronic heart failure aged $<50$ years than in patients aged $\geq 80$ years] or the longer survival of younger participants recruited in trials of chronic heart failure patients. When the independent variables were combined in predictive models, they provided reasonable c-statistics of $0.74-$ 0.76. Indeed, this is comparable with models for prediction of diabetes in the general population, despite not containing any direct glucose-related measures. ${ }^{25}$

Various strengths and weaknesses of the data contained in this report warrant discussion. This is the first randomized trial to report the effect of MR antagonist therapy on new-onset diabetes, and participants were well phenotyped at baseline. While diabetes was physician-diagnosed and not based on trial-required measurements of fasting plasma glucose, participants were specifically asked about new-onset diabetes at each trial visit. Data for family history of diabetes were not available. The numbers of participants that developed diabetes was relatively small, so statistical power to detect a modest effect of eplerenone on new-onset diabetes was limited.

In summary, information available from commonly measured clinical and laboratory variables predicts the development of newonset diabetes in patients with symptomatically mild systolic heart failure with similar accuracy to models used in other populations. Treatment of these patients with eplerenone had no effect on the development of diabetes compared with placebo.

\section{Supplementary material}

Supplementary material is available at European Journal of Heart Failure online.

\section{Funding}

EMPHASIS-HF was supported by the study sponsor, Pfizer. 
Conflicts of interest: D.J.v.V., H.K., K.S., B.P, S.J.P., F.Z., and J.J.V.M are members of the EMPHASIS-HF Writing Committee and report receiving support from the study sponsor, Pfizer, for participation in and travelling to meetings of the committee. H.S. and J.V. are currently employed by Pfizer and own stock in Pfizer, Inc., the makers of eplerenone. All other authors have no conflicts to declare. The sponsor was responsible for data management and final data analyses. The authors had full access to all data, and were responsible for the interpretation of the results, the development and writing of the manuscript, and the decision to submit for publication. Members of the medical and scientific departments of the sponsor, Pfizer supported the work of the authors, but did not make any scientific or research decisions independent of the authors.

\section{References}

1. MacDonald MR, Petrie MC, Hawkins NM, Petrie JR, Fisher M, McKelvie R, Aguilar D, Krum H, McMurray JJ. Diabetes, left ventricular systolic dysfunction, and chronic heart failure. Eur Heart J 2008;29:1224-1240.

2. Preiss D, Zetterstrand S, McMurray JJ, Ostergren J, Michelson EL, Granger CB, Yusuf S, Swedberg K, Pfeffer MA, Gerstein HC, Sattar N. Predictors of development of diabetes in patients with chronic heart failure in the Candesartan in Heart Failure Assessment of Reduction in Mortality and Morbidity (CHARM) program. Diabetes Care 2009;32:915-920.

3. Torp-Pedersen C, Metra M, Charlesworth A, Spark P, Lukas MA, Poole-Wilson PA, Swedberg K, Cleland JG, Di Lenarda A, Remme WJ, Scherhag $A ;$ COMET investigators. Effects of metoprolol and carvedilol on pre-existing and new onset diabetes in patients with chronic heart failure: data from the Carvedilol Or Metoprolol European Trial (COMET). Heart 2007;93:968-973.

4. Elliott WJ, Meyer PM. Incident diabetes in clinical trials of antihypertensive drugs: a network meta-analysis. Lancet 2007;369:201-207.

5. McMurray JJ, Holman RR, Haffner SM, Bethel MA, Holzhauer B, Hua TA, Belenkov Y, Boolell M, Buse JB, Buckley BM, Chacra AR, Chiang FT, Charbonnel B, Chow CC, Davies MJ, Deedwania P, Diem P, Einhorn D, Fonseca V, Fulcher GR, Gaciong Z, Gaztambide S, Giles T, Horton E, Ilkova H, Jenssen T, Kahn SE, Krum H, Laakso M, Leiter LA, Levitt NS, Mareev V, Martinez F, Masson C, Mazzone T, Meaney E, Nesto R, Pan C, Prager R, Raptis SA, Rutten GE, Sandstroem H, Schaper F, Scheen A, Schmitz O, Sinay I, Soska V, Stender S, Tamás G, Tognoni G, Tuomilehto J, Villamil AS, Vozár J, Califf RM. Effect of valsartan on the incidence of diabetes and cardiovascular events. N Engl J Med 2010;362:1477-1490.

6. Yusuf S, Ostergren JB, Gerstein HC, Pfeffer MA, Swedberg K, Granger CB, Olofsson B, Probstfield J, McMurray JV; Candesartan in Heart Failure-Assessment of Reduction in Mortality and Morbidity Program Investigators. Effects of candesartan on the development of a new diagnosis of diabetes mellitus in patients with heart failure. Circulation 2005;112:48-53.

7. Yamaji M, Tsutamoto T, Kawahara C, Nishiyama K, Yamamoto T, Fujii M, Horie M. Effect of eplerenone versus spironolactone on cortisol and hemoglobin $A(c)$ levels in patients with chronic heart failure. Am Heart J 2010;160:915-921.

8. Matsumoto S, Takebayashi K, Aso Y. The effect of spironolactone on circulating adipocytokines in patients with type 2 diabetes mellitus complicated by diabetic nephropathy. Metabolism 2006;55:1645-1652.

9. Davies JI, Band M, Morris A, Struthers AD. Spironolactone impairs endothelial function and heart rate variability in patients with type 2 diabetes. Diabetologia 2004;47:1687-1694.
10. Swaminathan K, Davies J, George J, Rajendra NS, Morris AD, Struthers AD. Spironolactone for poorly controlled hypertension in type 2 diabetes: conflicting effects on blood pressure, endothelial function, glycaemic control and hormonal profiles. Diabetologia 2008;51:762-768.

11. Polyzos SA, Kountouras J, Zafeiriadou E, Patsiaoura K, Katsiki E, Deretzi G, Zavos C, Tsarouchas G, Rakitzi P, Slavakis A. Effect of spironolactone and vitamin $E$ on serum metabolic parameters and insulin resistance in patients with nonalcoholic fatty liver disease. J Renin Angiotensin Aldosterone Syst 2011;12. 498-503.

12. Zannad F, McMurray JJ, Drexler H, Krum H, van Veldhuisen DJ, Swedberg K, Shi H, Vincent J, Pitt B. Rationale and design of the Eplerenone in Mild Patients Hospitalization And Survlval Study in Heart Failure (EMPHASIS-HF). Eur J Heart Fail 2010;12:617-622

13. Zannad F, McMurray J], Krum H, van Veldhuisen DJ, Swedberg K, Shi H, Vincent J, Pocock SJ, Pitt B; EMPHASIS-HF Study Group. Eplerenone in patients with systolic heart failure and mild symptoms. N Engl ] Med 2011;364:11-21.

14. Centers for Disease Control and Prevention. Diabetes Data and Trends 2009; available at: http://www.cdc.gov/diabetes/statistics/incidence/fig3.htm (last accessed 2 February 2012)

15. Garg R, Hurwitz S, Williams GH, Hopkins PN, Adler GK. Aldosterone production and insulin resistance in healthy adults. J Clin Endocrinol Metab 2010;95: 1986-1990.

16. Catena C, Lapenna R, Baroselli S, Nadalini E, Colussi G, Novello M, Favret G, Melis A, Cavarape A, Sechi LA. Insulin sensitivity in patients with primary aldosteronism: a follow-up study. J Clin Endocrinol Metab 2006;91:3457-3463.

17. Kosmala W, Przewlocka-Kosmala M, Szczepanik-Osadnik H, Mysiak A, O'Moore-Sullivan T, Marwick TH. A randomized study of the beneficial effects of aldosterone antagonism on LV function, structure, fibrosis markers in metabolic syndrome. JACC Cardiovasc Imaging 2011;4:1239-1249.

18. Heianza Y, Hara S, Arase Y, Saito K, Totsuka K, Tsuji H, Kodama S, Hsieh SD, Yamada N, Kosaka K, Sone H. Low serum potassium levels and risk of type 2 diabetes: the Toranomon Hospital Health Management Center Study 1 (TOPICS 1). Diabetologia 2011;54:762-726.

19. Aksnes TA, Kjeldsen SE, Rostrup M, Storset O, Hua TA, Julius S. Predictors of new-onset diabetes mellitus in hypertensive patients: the VALUE trial. I Hum Hypertens 2008;22:520-527.

20. Sattar N, Scherbakova O, Ford I, O'Reilly DS, Stanley A, Forrest E, Macfarlane PW, Packard CJ, Cobbe SM, Shepherd J. Elevated alanine aminotransferase predicts new-onset type 2 diabetes independently of classical risk factors, metabolic syndrome, C-reactive protein in the west of Scotland coronary prevention study. Diabetes 2004;53:2855-2860.

21. Fraser A, Harris R, Sattar N, Ebrahim S, Davey SG, Lawlor DA. Alanine aminotransferase, gamma-glutamyltransferase,, incident diabetes: the British Women's Heart, Health Study, meta-analysis. Diabetes Care 2009;32:741-750.

22. Tenenbaum A, Motro M, Fisman EZ, Leor J, Boyko V, Mandelzweig L, Behar S. Functional capacity impairment in patients with coronary artery disease: prevalence, risk factors and prognosis. Cardiology 2003;100:207-215.

23. lannello S, Milazzo P, Belfiore F. Animal and human tissue Na,K-ATPase in obesity and diabetes: a new proposed enzyme regulation. Am J Med Sci 2007;333:1-9.

24. Bagrov YY, Manusova NB, Frolova EV, Egorova IA, Kashkin VA, Tapilskaya NI, Fedorova OV, Bagrov AY. Endogenous sodium pump inhibitors, diabetes mellitus and preeclampsia. Preliminary observations and a hypothesis. Pathophysiology 2007;14:147-151.

25. Dankner R, Abdul-Ghani MA, Gerber Y, Chetrit A, Wainstein J, Raz I. Predicting the 20-year diabetes incidence rate. Diabetes Metab Res $\operatorname{Rev} 2007 ; 23$ : $551-558$. 